\title{
Juan A. Epple y Edson Faúndez V. (eds.), La casa del poeta no tiene llave. La poesía de Omar Lara, Puebla, Círculo de Poesía, 2011, 218 pp.
}

Omar Lara (nacido Nohualhue, un pueblo cerca de Nueva Imperial, Chile, en 1941) no es un poeta desconocido en España, teniendo en cuenta el reducido círculo de lectores españoles que leen poesía y que, a su vez, se interesan por la que viene del otro lado del Atlántico. En 1984 publicó Fugar con juego, en 2007 Papeles de Harek Ayun, y en 2009 La tierra prometida, pero si consideramos su larga e intensa trayectoria, quizás hasta el momento su difusión en España no ha sido todo lo esperable que debiera, tratándose de uno de los poetas más importantes vivos en lengua española actuales. Porque aunque pueda parecer más fácil el intercambio hoy día, a nivel poético, estético y en otras disciplinas sin recorrido comercial, sigue habiendo un abismo y aislamiento absolutos que parece bien difícil de solventarse. Es una pena pero es así, no hay fluidez. Y, además, también se hace evidente que en España existe una suerte de lastre histórico por el que no se muestra demasiada atención a los poetas de Hispanoamérica, y que todo lo que se publica «allá», al otro lado del Atlántico, no llega «acá», a este lado. Los poetas de allí necesitan a veces de no sé qué impulsos para que se les lea aquí. Sea como fuere, no se trata, en nuestro caso, de un autor novel: la obra de Omar Lara ha sido incluida en las más importantes antologías en Chile sobre todo, en Hispanoamérica y en España en concreto, entre las que destacan las que realizó Álvaro Salvador, Muestra de poesía hispanoamericana actual (34 nombres en 34 años: 1963-1997), (Granada: Maillot Amarillo, 1998), y La piel del jaguar: 25 poetas hispanoamericanos ante un nuevo siglo (Sevilla: Fundación José Manuel Lara, Colección Vandalia, 2006). A lo que hay que sumar su reconocida labor como traductor del rumano, con más de 20 poemarios y libros traducidos, lengua que aprendió durante los años de exilio, tras el golpe de Estado de 1973. En España sus traducciones se pueden encontrar en editoriales como Hiperión o Visor. Y no olvidamos en este breve recorrido por su trayectoria, que en los años sesenta fundó y dirigió el colectivo y la revista Trilce, de la que sigue siendo director. El homenaje vallejiano del título no será casual, y un poso - una asimilaciónvanguardista le acompañará siempre en sus composiciones, alternando lo mejor de esta herencia rompedora.

Omar Lara hace bueno el dicho ciceroniano ubi bene ibi patria (donde se está bien, allí está la patria), ya que tanto en sus décadas de exilio como en sus continuos viajes por el mundo, ha diversificado actividades, publicaciones, conferencias, etc. Si repasamos su biografía ligeramente, vemos que ha dado a la imprenta libros en países como Chile, Perú, Paraguay, México, Cuba, España, Italia o Rumanía, si no estamos olvidando alguno, y la cantidad de premios recibidos, tanto por su obra creativa como por su quehacer traductor, es ciertamente larga de enumerar y preferimos ahorrárnoslo en una reseña que viene a presentar un libro de crítica sobre su ingente y significativa obra. Aunque desde su vuelta del exilio - Perú, Rumanía y España - se radicó en Concepción (Chile), sus idas y venidas por la geografía hispanoamericana y europea son constantes. Así, mezclado con su voluntad de vivir, de viajar, de explorar el mundo, se halla el sentimiento de regreso, de vida apacible en Concepción, junto a su familia y en la ciudad donde reside habitualmente y donde en 1997 puso en marcha de nuevo Trilce, en su tercera época (la segunda había sido en Madrid en los años ochenta). Trilce es sin duda una de las mejores revistas literarias de Chile desde su fundación.

Llama poderosamente la atención en la poesía de los grandes poetas exiliados cómo esta condición parece haberles pertenecido desde antes de que el exilio se llevara a cabo. La condición de exiliado es un estado de ánimo, una forma de no encajar en el mundo, una suerte de errancia vital o búsqueda perpetua... Y desde 1964, fecha en que publica su primer libro, Argumento del día, puede observarse esta constante o inquietud, como en este poema: desolación, interrogantes sobre la naturaleza del ser...

DESPUÉS DE TODO 
¿Se puede escribir sobre los techos

y su impasible sumisión?

Hoy hablaré de las manzanas,

de las esquinas jubilosas,

de los entonces,

de mi ayer.

Porque después de todo

no sé qué hacer

con el mañana.

Porque después de todo,

la lluvia oblicua,

los telegramas innecesarios,

las tristes máscaras carnavalescas,

las camisas con una firma

de la amiga.

Porque después de todo

qué vale más

no importa tanto,

apenas

como de aquí a la muerte.

Porque después de todo

porque antes,

porque encima y al

lado de las cosas,

porque al final,

no estamos más que preguntando.

No estamos más que preguntando.

Algo de esto, pero sobre todo análisis mucho más elaborados, de primera línea, como corresponde a un volumen de crítica de estas características, puede leerse en La casa del poeta no tiene llave. La poesía de Omar Lara, colectánea que se ha publicado en la joven editorial mexicana, radicada en Puebla, Círculo de Poesía - también poseen página web, muy activa, por cierto: www.circulodepoesia.com - , y que viene a homenajear, como ya hemos dicho, a uno de los poetas más interesantes de las últimas décadas en nuestra lengua. La casa del poeta no tiene llave está tomado de unos versos de Jorge Teillier dedicados a Omar Lara. Juan A. Epple y Edson Faúndez V. han editado un volumen que recoge artículos inéditos y algunos otros que estaban dispersos y que acompañaron ediciones del chileno, o destacaron en el largo ya repertorio de los estudios sobre Omar Lara. Autores de uno y otro lado del Atlántico - más de dos docenas - se han juntado para celebrar esta poesía que a nosotros no nos ha pasado desapercibida, y sobre la cual lanzamos una invitación a los lectores españoles. Preferimos no citar a todos los participantes de la obra porque resultaría redundante, pero basten estas palabras para dejar constancia de la importancia de este volumen y de la iniciativa. Esperamos ver publicado en España una recopilación de la poesía de Omar Lara cuanto antes.

Juan Carlos Abril 